\title{
TRINTA ANOS DO CÉSIO 137: TRAJETÓRIA LEGAL DA POLÍTICA NACIONAL BRASILEIRA NA PREVENÇÃO DE ACIDENTES RADIOATIVOS.
}

\author{
Valmir César Pozzetti ${ }^{1}$ \\ Wagner Robério Barros Gomes ${ }^{2}$
}

RESUMO: O objetivo desta pesquisa foi de verificar os fatos históricos ocorridos no acidente Césio 137, em Goiânia, e analisar a legislação a respeito do tema, verificando se o Brasil avançou no tocante à prevenção de acidentes radioativos. Concluiu-se que, embora, o Brasil tenha avançado em aspectos normativos, a trajetória legislativa focou no uso da radioatividade para fins de domínio da técnica de energia nuclear e não avançou quanto ao desenvolvimento de uma Política Nacional de Prevenção de Acidentes Radioativos. A metodologia utilizada nesta pesquisa foi o método dedutivo, quanto aos meios a pesquisa foi bibliográfica e quanto aos fins, qualitativa.

PALAVRAS-CHAVE: radioatividade; prevenção; política nuclear brasileira; acidente radioativo; Césio-137.

\section{THIRTY YEARS OF CESIUM 137: TRAJECTORY OF BRAZILIAN POLICIES ON PREVENTION OF RADIOLOGICAL ACCIDENTS}

SUMMARY: the objective of this research was to verify the historical facts that occurred in the Caesium 137 in Goiânia accident, and analyze the legislation on the subject, checking if Brazil has advanced as regards the prevention of radioactive accidents. It was concluded that, although Brazil has advanced, in regulatory aspects, legislative career focused in the use of radioactivity for mastery of technique nuclear energy and has not advanced as far as the development national policy of prevention of Radioactive Accidents. for mastery of technique of nuclear energy and has not advanced as the development of a national policy.

KEYWORDS: radioactivity; prevention; Brazilian nuclear policy; accident radioactive; caesium-137

\footnotetext{
${ }^{1}$ Doutor em Biodireito/Direito Ambiental pela Université de Limoges/França. Professor Adjunto da Universidade Federal do Amazonas e Professor Adjunto da Universidade do Estado do Amazonas. E-mail: v_pozzetti@hotmail.com

${ }^{2}$ Mestrando do Programa de Mestrado em Direito Ambiental, da Universidade do Estado do Amazonas. E-mail: wagnner.gomess@gmail.com
} 


\section{TRINTA ANOS DO CÉSIO 137: TRAJETÓRIA LEGAL DA POLÍTICA NACIONAL BRASILEIRA NA PREVENÇÃO DE ACIDENTES RADIOATIVOS}

\section{INTRODUÇÃO}

A descoberta da radioatividade no final do século XIX, impulsionou diversos setores sociais, tais como: bélico, medicina, indústria, etc. No entanto, a novidade, também, trouxe preocupações quanto aos efeitos negativos que ela provocaria no meio ambiente e no organismo das pessoas. Por conseguinte, as preocupações se agravaram diante de acidentes ao redor do mundo envolvendo substâncias radioativas que deixaram rastros de destruição e mortes.

No Brasil, na cidade de Goiânia - GO, em 13 de setembro de 1987, uma série de eventos trágicos culminaram no maior acidente radioativo em zona urbana do país: a abertura indevida de uma cápsula com apenas 19g de Césio -137 que era utilizada para tratamento radioterápico. Uma quantidade irrisória, mas que causou a contaminação de milhares de pessoas e causou dezenas de mortes. Eventos como este causam preocupações na comunidade científica, pois os efeitos danosos trazem prejuízos de ordem sanitária e ambiental que em razão da abrangência da contaminação tendem a ficar fora de controle.

A problemática desta pesquisa reside na falta ou ausência de controle, ou seja: como desenvolver técnicas positivas através do uso da radioatividade sem causar externalidades negativas incontroláveis ao meio ambiente e a saúde da coletividade? No caso do acidente Césio-137 em Goiânia, o despreparo dos órgãos públicos quando da ocorrência do dano nuclear ambiental, mesmo o país já tendo uma Comissão Nacional de Energia Nuclear (CNEN) constituída desde 1956, evidenciou-se na ausência de Políticas Públicas Preventivas frente ao ineditismo do evento. Exemplo disso, a mão de obra selecionada para atuar na limpeza e remoção dos resíduos não usava equipamentos adequados de proteção, o que só fez aumentar o número de vítimas.

O objetivo geral é traçar uma linha histórica de como a questão do uso da radioatividade foi sendo inserida no ordenamento jurídico pátrio; buscando indícios de medidas preventivos frente a possíveis acidentes que envolvam radioatividade. Quanto ao aspecto metodológico, é empregada a pesquisa bibliográfica, sendo utilizado o método descritivo na análise dos dados. O marco histórico referencial do estudo foi o acidente Césio -137, ocorrido em Goiânia - GO, em 13 de setembro de 1987, tendo por base a legislação brasileira antes e depois do acidente.

Dessa forma, o desenvolvimento deste trabalho está dividido em três momentos distintos, mas que se relacionam entre si. No primeiro momento, dá-se início ao contexto histórico-jurídico no Brasil, 
antes do acidente com o Césio-137. No segundo, trata-se do acidente, suas causas, consequências e o papel da Comissão Nacional de Energia Nuclear. E por fim, no terceiro momento, segue-se com o constructo histórico-jurídico pós Constituição de 1988 até os dias atuais.

\section{O contexto histórico-jurídico pré-acidente.}

O Brasil na década de 30, iniciou suas pesquisas sobre tecnologia nuclear; mas, é com a II Guerra Mundial que o interesse brasileiro se sistematiza. Os Estados Unidos da América era o único país que dominava a tecnologia e a empregou, como armamento bélico, contra o Japão na II Guerra Mundial, nos ataques à Hiroshima e Nagasaki. Embora, o país norte-americano tenha criado a lei McMahon que limitava intercâmbio de informações nucleares com outros países, a sua constante necessidade de obter elementos radioativos fez com que este ele assinasse em 1945 com o Brasil, um acordo no qual previa a exportação, de terras brasileiras, de matéria-prima para processos nucleares. (KURAMOTO, 2002, p.380)

Rico em minérios, é nesse contexto que o Brasil em 1956 cria a Comissão Nacional de Energia Nuclear (CNEN) como um órgão superior subordinado a Presidência da República responsável pelo desenvolvimento da Política Nacional de Energia Nuclear.

No início da década de 60, a Comissão é transformada em autarquia federal por meio da Lei $n^{0} 4.118 / 1962$, que trata da estrutura e organização do Comissão Nacional de Energia Nuclear - CNEN. A lei também forneceu conceitos para: elemento nuclear, minério nuclear, urânio enriquecido, material nuclear, material fértil, material físsil especial e subproduto nuclear.

Em 1971, a Lei ${ }^{0} 5.740$ autorizou a Comissão Nacional de energia Nuclear a constituir a sociedade por ações Companhia Brasileira de Tecnologia Nuclear - C.B.T.N. que, segundo o art. $4^{\circ}$, poderá fazer parceiras com entidades públicas ou privadas, com ou sem remuneração ou ressarcimento de despesas.

Quatro anos depois, a Lei $\mathrm{n}^{0} 6.189 / 1974$, alterou as Leis $\mathrm{n}^{\circ} 4.118 / 1962$ que criou a Comissão Nacional de Energia Nuclear - CNEN e a Lei n 5.740/1971, que criou a Companhia Brasileira de Tecnologia Nuclear - CBTN. Pela lei de 1974 a Companhia Brasileira de Tecnologia Nuclear passa a denominar-se Empresas Nucleares Brasileiras Sociedade Anônima 


\section{TRINTA ANOS DO CÉSIO 137: TRAJETÓRIA LEGAL DA POLÍTICA NACIONAL BRASILEIRA NA PREVENÇÃO DE ACIDENTES RADIOATIVOS}

- NUCLEBRÁS. A lei estabelece, em seu art. $1^{\circ}$, que a União exercerá o monopólio sobre as atividades nucleares por meio da CNEN e da NUCLEBRÁS. A norma também estabelece uma ampla competência de atuação para a CNEN quanto à questão nuclear.

No ano de 1977, a Lei $n^{\circ} 6.453$ dispôs sobre a responsabilidade civil por danos nucleares e a responsabilidade criminal por atos relacionados com atividades nucleares. A Lei fornece conceitos legais para: operador, combustível nuclear, produtos ou rejeitos radioativos, material nuclear, reator nuclear, instalação nuclear, dano nuclear, acidente nuclear e radiação ionizante. Vejamos as descrições de alguns destes conceitos:

\footnotetext{
Art . $1^{\circ}$ - Para os efeitos desta Lei considera-se:

I - "operador", a pessoa jurídica devidamente autorizada para operar instalação nuclear;

(...) omissis

III - "produtos ou rejeitos radioativos", os materiais radioativos obtidos durante o processo de produção ou de utilização de combustíveis nucleares, ou cuja radioatividade se tenha originado da exposição às irradiações inerentes a tal processo, salvo os radioisótopos que tenham alcançado o estágio final de elaboração e já se possam utilizar para fins científicos, médicos, agrícolas, comerciais ou industriais; (...) omissis

VII - "dano nuclear", o dano pessoal ou material produzido como resultado direto ou indireto das propriedades radioativas, da sua combinação com as propriedades tóxicas ou com outras características dos materiais nucleares, que se encontrem em instalação nuclear, ou dela procedentes ou a ela enviados;

VIII - "acidente nuclear", o fato ou sucessão de fatos da mesma origem, que cause dano nuclear;

IX - "radiação ionizante", a emissão de partículas alfa, beta, neutrons, ions acelerados ou raios $\mathrm{X}$ ou gama, capazes de provocar a formação de ions no tecido humano.

(...) omissis

Art . $3^{\circ}$ - Será também considerado dano nuclear o resultante de acidente nuclear combinado com outras causas, quando não se puderem distinguir os danos não nucleares.
}

Sobre a responsabilidade civil por danos nucleares, dispõe o art. $4^{0}$ que ela “será exclusiva do operador da instalação nuclear, nos termos desta Lei, independentemente da existência de culpa, a responsabilidade civil pela reparação de dano nuclear causado por acidente nuclear”. O respectivo artigo lista três hipóteses em três incisivos que fazem referência a instalação nuclear, ou seja, danos relacionados a material oriundos e/ou destinados as usinas nucleares.

Quanto a responsabilidade criminal, dentre as hipóteses tipificadas a partir do art. 20, temos como exemplos: 
Art . 20 - Produzir, processar, fornecer ou usar material nuclear sem a necessária autorização ou para fim diverso do permitido em lei.

Pena: reclusão, de quatro a dez anos.

Art . 21 - Permitir o responsável pela instalação nuclear sua operação sem a necessária autorização.

Pena: reclusão, de dois a seis anos.

Art . 22 - Possuir, adquirir, transferir, transportar, guardar ou trazer consigo material nuclear, sem a necessária autorização.

Pena: reclusão, de dois a seis anos.

(...) omissis

Art . 26 - Deixar de observar as normas de segurança ou de proteção relativas à instalação nuclear ou ao uso, transporte, posse e guarda de material nuclear, expondo a perigo a vida, a integridade física ou o patrimônio de outrem.

Pena: reclusão, de dois a oito anos.

Art . 27 - Impedir ou dificultar o funcionamento de instalação nuclear ou o transporte de material nuclear.

Pena: reclusão, de quatro a dez anos.

Dessa forma, se verifica que as questões relacionadas as responsabilidades civil por danos nucleares e a criminal por atos relacionados com atividades nucleares, estão relacionadas as atividades desenvolvidas ou correlatas as usinas nucleares e aos materiais radioativos nelas empregados ou a elas destinado.

Assim, essas eram as normas presentes no ordenamento jurídico Brasileiro no final da década de 80 - voltadas as questões das usinas nucleares - quando ocorreu o acidente com Césio-137 em Goiânia-GO. A radioatividade em regra pode ser utilizada para fins bélicos, radiológicos e produção de energia nuclear. O Acidente em Goiânia causado pela Césio-137, foi uma contaminação radioativo por fonte radiológica. Não havia previsão legal específica que regulamentasse e/ou responsabilizasse agentes por danos oriundos de fontes radiológicas, muito menos politicas preventivas para acidentes dessa natureza.

\section{O Acidente Césio-137 em Goiânia-GO.}

Em 1987 ocorreu no Brasil o maior acidente radioativo em zona urbana do planeta: o Césio 137, em Goiânia - GO. No entanto, é importante entender os eventos pretéritos que ensejaram este evento fatídico.

Segundo Vieira (2013, p. 217), no início dos anos 70, a Sociedade São Vicente de Paulo, que administrava a Santa Casa de Misericórdia de Goiânia, emprestou seu terreno para que fosse construído o Instituto Goiano de Radiologia. O Instituto, como contrapartida, viabilizaria exames gratuitos aos pacientes da Santa Casa. 


\section{TRINTA ANOS DO CÉSIO 137: TRAJETÓRIA LEGAL DA POLÍTICA NACIONAL BRASILEIRA NA PREVENÇÃO DE ACIDENTES RADIOATIVOS}

No entanto, o Instituto Goiano de Radiologia não cumpriu sua parte do acordo e a Sociedade São Vicente de Paulo decidiu em 1984 vender o terreno para o Instituto de Previdência e Assistência do Estado de Goiás, antes mesmo que o antigo locatário fosse despejado. Em 1985, O Instituto Radiológico mudou de endereço deixando para trás equipamentos antigos, dentre eles um aparelho radiológico contendo uma cápsula de Césio -137.

Ainda segundo a autora, os anos seguintes foram de litigio judicial. Em maio de 1987, o Instituto de Previdência começou a demolição do prédio no terreno, que foi interrompida por uma liminar judicial. O local ficou abandonado até que em setembro do mesmo ano, os equipamentos lá deixados despertaram o interesse de catadores de sucata. E, isso ocorreu no dia 13 de setembro de 1987, quando dois catadores de sucata adentraram na ruinas do prédio abandonado no centro de Goiânia, o antigo local do Instituto Goiano de Radiologia. De lá, retiraram um equipamento abandonado com o intuito de revender o chumbo que o revertia para o ferro-velho. (2013, p. 217)

A parte do aparelho que continha a cápsula de Césio-137 foi levada para residência de um dos catadores; sendo rompida a proteção que isolava o elemento radioativo que foi, por conseguinte, liberado no ambiente.

A cápsula foi vendida para o dono de um ferro-velho que em uma noite de setembro percebe que os grãos contidos no objeto emitem uma luz azul. Fascinado com a descoberta, ele distribui o achado entre familiares e amigos. O fato só chegou a conhecimento púbico quase 16 dias depois do desmonte da cápsula, quando ela foi entregue na Vigilância Sanitária da Seccional de Goiânia por um casal que desconfiou que o que havia nela, estava fazendo mal para sua família. Mas, a contaminação já tinha se alastrado. Segundo Chaves (2007, p.01):

“... os efeitos do acidente atingiram homens, mulheres, crianças, animais domésticos, casas, ruas, chegando até à atmosfera. A radiação, oficialmente, atingiu uma área de $2.000 \mathrm{~m}^{2}$ não contínuos, infiltrandose no solo até a profundidade de $50 \mathrm{~cm}$, em alguns pontos, provocando a necessidade da derrubada de árvores e plantas, num raio de $100 \mathrm{~m}$ das zonas afetadas...”

Ou seja, as pessoas contaminadas se tornaram fontes irradiadoras pela cidade e sentindo os sintomas da radioatividade: vômitos, queimaduras na pele, perda de cabelo, etc., sem saber 
do que se tratava, procuravam hospitais e ambulatórios - o que ampliava os locais de irradiação e contaminação; pois se tornaram também, fontes irradiadoras.

Um fato interessante, neste momento, relatado por Bufáiçal (2012, p. 36-38), mostra que o Corpo de Bombeiros foi acionado para resolver o problema de um suposto vazamento de gás. Quando chegaram na Vigilância Sanitária da Seccional de Goiânia, verificaram o cilindro dentro de um saco e por não saberem do que se tratava, um dos bombeiros sugeriu ao $1^{\circ}$ Tenente que comandava a operação, que o objeto fosse jogado no Rio Meia-Ponte. O fato só não ocorreu porque no momento, um físico apareceu no local os impedira de proceder de tal modo.

Por fim, as autoridades públicas, tomando conhecimento do que se tratava, a Vigilância Sanitária acionou a Comissão Nacional de Energia Nuclear e iniciaram o processo para sanar a situação - os impactos no meio ambiente e na saúde da coletividade.

\subsection{A atuação da Comissão Nacional de Energia Nuclear}

O Governo de Juscelino Kubitschek criou em 10 de outubro de 1956 a Comissão Nacional de Energia Nuclear (CNEN). Segundo Andrade (2010, p.230), o CNE surgiu como um “órgão superior de planejamento subordinado à presidência da República, sendo responsável pela política nacional de energia atômica em todas as fases e aspecto”.

Era responsabilidade do CNEN, a vistoria da Bomba de Césio-137 que causou o acidente radioativo em Goiânia. O que não ocorria. Conforme descreve Gabeira (1987, p. 02) “a última pessoa que inspecionou a bomba, em nome da comissão Nacional de Energia Nuclear, foi um físico chamado João Emílio. Isto em 1977, dez anos antes do acidente”. E como se verificou nos artigos científicos pesquisados até o momento, as instituições envolvidas no litígio do terreno onde ficava o Instituto Radiológico em que o equipamento fora abandonado, também não tiveram interesse em comunicar o abandono da capsula ao CNEN.

Outro ponto que chamou atenção foi quando o CNEN foi notificado para agir frente ao acidente em Goiânia. O órgão não estava preparado e reagiu de forma improvisada. Um 
exemplo disso, explicitado por Lobo (2014, p. 429), menciona que o CNEN “...contratou trabalhadores para executar a descontaminação do local sem nenhum preparo ou mesmo conhecimento do perigo que corriam. ”

No relato de Bufáiçal (2012, p. 31), a situação era tão crítica em tantos aspectos que um físico paulista, na época, diretor-chefe do Departamento de Instalações de Materiais Nucleares da CNEN, teria escrito uma carta onde dizia que em razão do acidente, a cidade de Goiânia precisava ser evacuada. Mas, não foi o que ocorreu.

Diversos órgãos atuaram conjuntamente na resolução do acidente, mas o destaque recai sobre CNEN por ser órgão responsável por organizar as linhas de trabalho. Os 43 técnicos de desembarcaram em Goiânia tiveram dificuldades iniciais, já que seu preparo era para atuar em acidentes com reatores nucleares. O referencial deles era o acidente em Chernobyl, mas se deparam com uma situação completamente diferente. Em Chernobyl houve a explosão de um reator e a contaminação principal ocorreu por ação de um vento forte. No caso do Césio-137, seu estado era sólido (pó, grãos) e precisava ser encontrado e isolado. (GABEIRA, 1987, p.04).

Ainda segundo Gabeira (1987, p.12), quanto aos habitantes, a monitoração e descontaminação começou a ser realizada no Estádio Olímpico da cidade de Goiânia. O procedimento era feito basicamente com água sabão e vinagre. Os casos mais graves, precisam também de um tipo de antídoto chamado azul-da-prússia. O problema era que o Brasil não o tinha em estoque; era possível fabricá-lo, mas não se conhecia a técnica. Enfim, o remédio foi comprado às pressas dos EUA.

Sobre os rejeitos radioativos, as 13 toneladas geradas pelo acidente foram desde 1987 transferidas para a cidade de Abadia a 20km de Goiânia, sob fortes protestos da população. Em 1997 a CNEN construiu na cidade, mais especificamente, no Parque Estadual Telma Ortegal, um depósito definitivo para os rejeitos e uma filial do CNEN para que técnicos ligados a Diretoria de Pesquisa e Desenvolvimento monitorassem o local constantemente, que foi projetado para resistir por uns 300 anos. (CORREIO BRASILIENSE, 2017).

Ainda segundo a matéria do Correio Brasiliense, sobre as vítimas fatais: 
“As quatro vítimas que morreram no período mais crítico do acidente foram enterradas em caixões lacrados de fibra de vidro revestidos com chumbo para prevenir que a radiação não contaminasse o solo e os lençóis freáticos. O peso de cada um era mais de $700 \mathrm{~kg}$ e tiveram que ser colocados com guindastes nas covas - também cobertas por larga camada de concreto. No cemitério estão dispostos lado a lado e um grande vão os separam de outras lápides, que seguem a descida do terreno” (2017).

Na esfera judicial, os protagonistas que deram causa para que o acidente ocorresse também foram indiciados como responsáveis. A Ação Civil Pública, nº 95.8505-04 de autoria do Ministério Público Feral, tinha como polo passivo: União Federal, CNEN - Comissão Nacional de Energia Nuclear, O Estado de Goiás - IPASGO: Instituo de Previdência e Assistência Social do Estado de Goiás e; Carlos de Figueiredo Bezerril, Criseide Castro Dourado e Orlando Alves, Flamarion Barbosa e Goulart e Amaurillo Monteiro de Oliveira - os responsáveis pelo Instituto Goiano de Radiologia.

\section{O Contexto histórico-jurídico pós Constituição de 1988.}

Quase 01 (um) ano após o acidente do Césio-137 em Goiânia-GO, em 05 de outubro de 1988 foi promulgada a nova Constituição da República Federativa do Brasil que trouxe inovações em diversas áreas. Boa parte das normas sobre política nuclear foram recepcionadas pela nova Carta Constitucional.

Sobre a temática nuclear, percebe-se a continuidade do monopólio da União. Os artigos que explicitam o tratamento dado pela Constituição de 1988 são: artigos 21 e 22 sobre competência exclusiva e privativa:

Art. 21. Compete a União:

(...) omissis

XXIII - explorar os serviços e instalações nucleares de qualquer natureza e exercer monopólio estatal sobre a pesquisa, a lavra, o enriquecimento e reprocessamento, a industrialização e o comércio de minérios nucleares e seus derivados, atendidos os seguintes princípios e condições:

a) toda atividade nuclear em território nacional somente será admitida para fins pacíficos e mediante aprovação do Congresso Nacional;

b) sob regime de permissão, são autorizadas a comercialização e a utilização de radioisótopos para a pesquisa e usos médicos, agrícolas e industriais; (Redação dada pela Emenda Constitucional ${ }^{\circ} 49$, de 2006)

c) sob regime de permissão, são autorizadas a produção, comercialização e utilização de radioisótopos de meia-vida igual ou inferior a duas horas; (Redação dada pela Emenda Constitucional no 49, de 2006)

d) a responsabilidade civil por danos nucleares independe da existência de culpa; (Redação dada pela Emenda Constitucional n 49, de 2006)

(...) omissis 
Art. 22. Compete privativamente à União legislar sobre:

(...)

XXVI - atividades nucleares de qualquer natureza; (BRASIL, 1988)

O tratamento dado pela Constituição de 1988 a questão nuclear reflete a importância da questão da segurança nacional. Os minérios nucleares tanto podem ser utilizados para produção de energia elétrica quanto para a produção de armamento nuclear altamente destrutivo. A competência do art. 2, XXIII, é exclusiva e não pode ser delegada, já a do art. 22, XXVI, competência privativa, há de ser interpretada em conjunto com o art. 21, XXIII, a. Qualquer atividade nuclear deve ser autorizada pelo Congresso Nacional e para fins pacífico.

No tocante ao o Capítulo I - Dos Princípios Gerias da Atividade Econômica, o Art. 177, $\mathrm{V}$, destaca o monopólio estatal do setor empresarial nuclear. Vejamos:

Art. 177. Constituem monopólio da União:

V - a pesquisa, a lavra, o enriquecimento, o reprocessamento, a industrialização e o comércio de minérios e minerais nucleares e seus derivados, com exceção dos radioisótopos cuja produção, comercialização e utilização poderão ser autorizadas sob regime de permissão, conforme as alíneas $b$ e $c$ do inciso XXIII do caput do art. 21 desta Constituição Federal. (Redação dada pela Emenda Constitucional n ${ }^{\circ} 49$, de $\underline{2006)}$

(...) omissis

$\S 3^{\circ}$ A lei disporá sobre o transporte e a utilização de materiais radioativos no território nacional. (Renumerado de $\S 2^{\circ}$ para $3^{\circ}$ pela Emenda Constitucional $n^{\circ}$ 9, de 1995) (BRASIL, 1988)

Sobre a proteção do meio ambiente, o art. 225, § $6^{\circ}$, atentando para os riscos da atividade nuclear ao meio ambiente e às pessoas, determina que:

Art. 225. Todos têm direito ao meio ambiente ecologicamente equilibrado, bem de uso comum do povo e essencial à sadia qualidade de vida, impondo-se ao Poder Público e à coletividade o dever de defendê-lo e preservá-lo para as presentes e futuras gerações.

(...)

$\S 6^{\circ}$ As usinas que operem com reator nuclear deverão ter sua localização definida em lei federal, sem o que não poderão ser instaladas. (BRASIL,1988)

Ainda sobre a questão da abordagem do tema radioatividade na Constituição Federal de 1988, na questão da saúde. O art. 200, VII, explicita a participação do Sistema Único de Saúde - SUS, no controle e fiscalização de substâncias radioativas, suplementando as atividades e contribuindo para a redução dos ricos dessas substâncias para a saúde individual e coletiva da população. Dispõe o artigo: 
Art. 200. Ao sistema único de saúde compete, além de outras atribuições, nos termos da lei:

(..) omissis

VII - participar do controle e fiscalização da produção, transporte, guarda e utilização de substâncias e produtos psicoativos, tóxicos e radioativos; (BRASIL,1988)

Dessa forma, verifica-se que os artigos da Constituição, que explicitamente abordam a questão da radioatividade, em sua maioria, dão ênfase para a questão nuclear no viés econômico. Embora, se observe uma abordagem nos capítulos referentes ao meio ambiente e a saúde, não se verificar nenhuma referência explícita a uma Política Nacional de Prevenção para Acidentes Nucleares. Mesmo, a Carta Magna tendo abordado o viés radiológico do uso da radioatividade, no art. 21, inciso XXIII, alíneas “b”, ” c”, e “d”, e art. 177, inciso V, - o enfoque é econômico.

É importante atentar para o fato de que acidentes radioativos decorrentes de atividades nucleares e/ou radiológicas no meio ambiente tendem a tomar proporções gigantescas e os rejeitos radioativos levam centenas de anos para que cessem seu processo de irradiação. A Constituição Federal, tendo sido promulgado praticamente um ano depois do acidente Césio137 em Goiânia-GO, não trouxe, sequer, um artigo tratando da radioatividade, no Brasil, com viés preventivo.

Em 1993, cinco anos após promulgação da CRFB/1988, em 1993, o Brasil incorporou a Convenção de Viena de 1963 sobre responsabilidade civil por danos nucleares, por meio do o Decreto $n^{\circ}$ 911/1993. Segundo Assis (2014, p. 100):

\footnotetext{
Os artigos da Convenção provocaram discussões sobre sua conformidade com a $\mathrm{CF} / 88$ que adotou a responsabilidade ampla e irrestrita do agente causador do dano de dano nuclear. No caso do limite indenizatório do art. V, [...], a Constituição não o autoriza. No caso das excludentes de responsabilidade que cuida o art. IV, o Decreto $n^{\circ}$ 911/1993 provocou questionamentos sobre a adoção da teoria do risco integral ou da teoria do risco administrativo, [...], não houve alteração da responsabilidade objetivo do causador do dano.
}

Assim, considera-se que o Decreto nº 911/1993 não fez alteração da responsabilidade prevista na CRFB/88 que se mantem objetiva, ampla e irrestrita. O que não há é consenso sobre a modalidade de risco adotada pela convenção. 
Em o 2001 foi sancionada a Lei $\mathrm{n}^{0}$ 10.308, que dispôs sobre a seleção de locais, a construção, o licenciamento, a operação, a fiscalização, os custos, a indenização, a responsabilidade civil e as garantias referentes aos depósitos de rejeitos radioativos. A Lei trouxe avanços sobre a questão da regularização dos depósitos radioativos.

$\mathrm{O}$ art. $2^{\circ}$ estabelece que a União, por meio da CNEN, é a responsável pelo destino final dos rejeitos radioativos produzidos em território nacional.

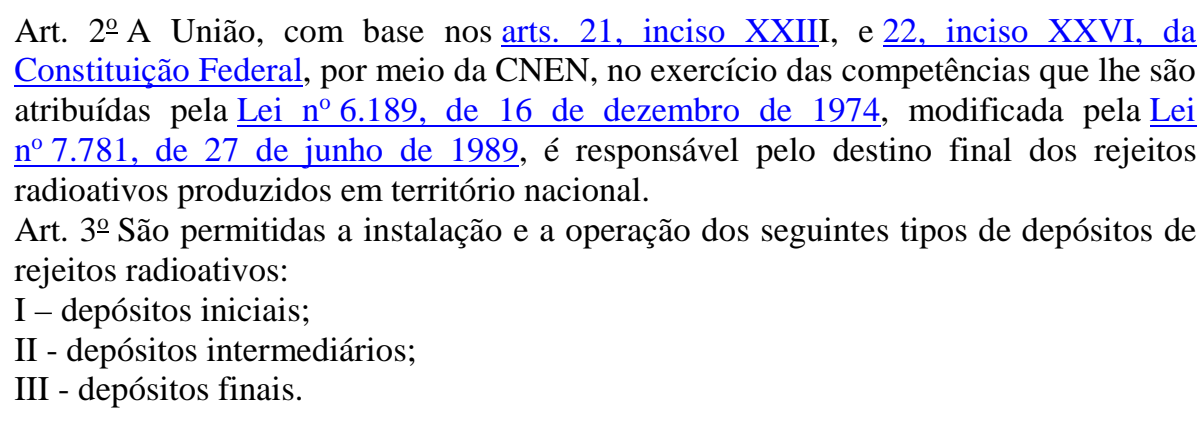

O art. $8^{\circ}$ determina que o projeto, construção e instalação de depósitos iniciais de rejeitos radioativos é de responsabilidade do titular da autorização outorgada pela CNEN, já o art. $9^{\circ}$ determina que a responsabilidade pelos depósitos intermediários e finais é da CNEN.

\footnotetext{
Art. 80 O projeto, a construção e a instalação de depósitos iniciais de rejeitos radioativos são de responsabilidade do titular da autorização outorgada pela CNEN para operação da instalação onde são gerados os rejeitos.

Art. 9o Cabe à CNEN projetar, construir e instalar depósitos intermediários e finais de rejeitos radioativos.

Parágrafo único. Poderá haver delegação dos serviços previstos no caput a terceiros, mantida a responsabilidade integral da CNEN.
}

No ano de 2007 foi apresentado um projeto de lei na Câmara do Deputados pelo do ex-deputado Silvinho Peccioli. O Projeto de Lei da Câmara $n^{0}$ 2.078/2007, encontrasse parado na Comissão de Constituição e Justiça, em caráter terminativo desde 2013. Ele dispõe sobre o encerramento das atividades de uma instalação radiativa e a limitação de sua radiação residual. Sobre a explicação da ementa:

"Fixa limites para a radiação residual de instalação radiativa após o encerramento de
suas atividades; determina seja solicitado à autoridade federal competente autorização
para o encerramento de atividade de instalação radiativa; condiciona a concessão da
referida autorização para o encerramento da atividade e para a liberação da área para
uso irrestrito à prévia aprovação do relatório de levantamento radiométrico pela
autoridade federal responsável pelo licenciamento da instalação radiativa; atribui a
responsabilidade civil e criminal decorrente da operação das instalações radiativas ao 
titular da respectiva autorização até que a autoridade federal competente aprove o mencionado relatório de levantamento radiológico.

Assim, segundo a justificação do ex-deputado contida no PL nº 2.078/2007:

[... ] depois de desativadas, os locais onde funcionavam essas instalações radiativas deixam de ser classificados como área controlada. Por essa razão, antes que saiam do campo de atuação dos órgãos responsáveis pela segurança radiológica, há que se garantir que a radiação residual que porventura persista no local não exponha os novos usuários a doses excessivas. Ocorre que as normas brasileiras atuais não fixam esses limites máximos de exposição, evidenciando grave risco para os novos ocupantes dessas áreas.

Para sanar esta lacuna existente na legislação, apresentamos esta proposição, que determina que, antes de encerradas as atividades da instalação radiativa, deve-se certificar que a dose máxima a que os novos ocupantes da área poderão estar expostos $[\ldots]$

Do ponto de vista da necessidade de uma Política Nacional de Prevenção para Acidentes Radioativos, o PL n ${ }^{\circ}$ 2.078/200, se transformado em Lei, oferecerá bases para essa política. Não pelas questões da fiscalização e responsabilização criminal. Mas, por cobrar dos responsáveis pelas atividades que produzam relatórios quanto a emissão de radioatividade quando da desativação de um local e por estabelecer limites na dose exposição radioativa a que novos ocupantes da área estarão sujeitos.

Em 2001, o então senador Walter Pinheiro apresentou o Projeto de Lei do Senado n ${ }^{227}$, que visa destinar parte dos recursos dos royalties do petróleo e do Fundo Social à prevenção de desastres naturais ou provocados por vazamento radioativo e ao atendimento das populações atingidas. Na explicação da ementa:

\begin{abstract}
Altera a Lei no 9.478/97 - que dispõe sobre a política energética nacional, as atividades relativas ao monopólio do petróleo e institui o Conselho Nacional de Política Energética e a Agência Nacional do Petróleo - para determinar que no mínimo 20\% dos recursos transferidos aos estados e municípios pelo fundo especial previsto no $\S$ $4^{\circ}$ do art. 27 da Lei $n^{\circ}$ 2004/53 deverão ser destinados para prevenir desastres provocados por causas naturais ou por vazamento de elementos radioativos, bem como para atender à população e às áreas atingidas por esses desastres; remete a regulamento específico a previsão de um plano de contingência para os referidos desastres; estabelece, ainda no âmbito da alteração da Lei no 9.478/97, que nas áreas localizadas no pré-sal contratadas sob o regime de concessão, a parcela dos royalties que cabe à administração direta da União será destinada integralmente ao Fundo Social (art. 47 da Lei ${ }^{\circ}$ 12.531/2010); determina que no mínimo 20\% dos recursos transferidos pelo Fundo Especial deverão ser destinados para prevenir desastres provocados por causas naturais ou por vazamento de elementos radioativos, bem como para atender a população e as áreas atingidas por desastres; altera a Lei $\mathrm{n}^{\circ}$ 12.351/2010 - que dispõe sobre a exploração e a produção de petróleo, de gás natural e de outros hidrocarbonetos fluidos, sob o regime de partilha de produção, em áreas
\end{abstract}




\section{TRINTA ANOS DO CÉSIO 137: TRAJETÓRIA LEGAL DA POLÍTICA NACIONAL BRASILEIRA NA PREVENÇÃO DE ACIDENTES RADIOATIVOS}

do pré-sal e em áreas estratégicas; cria o Fundo Social - FS e dispõe sobre sua estrutura e fontes de recursos - para determinar que deverá ser contemplado pelos recursos do Fundo Social a prevenção de desastres naturais provocados por causas naturais ou por vazamento de elementos radioativos, bem como de atendimento à população e às áreas atingidas por desastres.

Diante do exposto, essa proposta de lei tem a iniciativa explicita de prevenção de desastres, vazamento de material radioativo por meio da previsão de um plano de contingência; e ainda, estabelece um fundo especial para a prevenção desse tipo de desastre e atendimento à população atingida por esse desastre. O Projeto de Lei do Senado n 227 ainda está em tramitação na respectiva casa legislativa, e encontra-se Comissão de Assuntos Econômicos do Senado desde 2015.

Em maio deste ano, a presidente da República, Dilma Rousseff, sancionou a Lei 12.646/2012, que instituiu o 13 de setembro como o Dia Nacional de Luta dos Acidentados por Fontes Radioativas. Há exatos 25 anos, em 13 de setembro de 1987, o Brasil foi surpreendido pelo maior acidente com materiais radioativos da história do país, que ficou conhecido como o acidente do Césio-137 e motivou a criação da data.

Por fim, o projeto de lei da Câmara n 127/2013 de autoria do deputado federal Antônio Bulhões que torna obrigatório o rastreamento de carga de material radioativo durante seu transporte. O Projeto está pronto para a deliberação no Plenário desde junho de 2017.

\section{Conclusão}

A radioatividade, apesar de ser uma descoberta recente para humanidade, pouco mais de um século, de um modo geral vem sendo muito utilizada para fins bélicos, de energia nuclear e radiológico. A má utilização desse fenômeno nuclear pode causar desastres ambientais em grande escola e comprometer a vidas das populações por eles afetadas. O caso Césio 137, em Goiânia, exemplifica a questão e evidencia a necessidade de uma Política Pública Nacional para a prevenção de Acidentes Radioativos. 
A problemática que se levantou nessa pesquisa foi: como desenvolver técnicas positivas através do uso da radioatividade sem causar externalidades negativas incontroláveis ao meio ambiente e a saúde da coletividade?

Estabeleceu-se como objetivo a importância de traçar uma linha histórica de como a questão do uso da radioatividade foi sendo inserida no ordenamento jurídico brasileiro; buscando indícios de medidas preventivos frente a possíveis acidentes.

O resultado da pesquisa foi a percepção de que o Brasil, desde a década de 1950 construiu suas políticas públicas sobre o uso da radioatividade com grande enfoco no domínio das técnicas para produção de energia nuclear. Mesmo com a promulgação da Constituição Federal de 1988, um ano após o acidente radiológico em Goiânia, pouco se avançou em Políticas Públicas de Prevenção de Acidentes Nucleares em âmbito legal. Na atualidade, algumas propostas de lei em trâmite tanto na Câmara dos Deputados quanto no Senado Federal buscam sanar alguns lapsos legislativos. Isso, 30 anos após o acidente radioativo com Césio-137, em Goiânia.

\section{Referências Bibliográficas}

ANDRADE, Ana Maria Ribeiro. "A criação da CNEN no contexto do governo JK". Parcerias Estratégicas, vol. 14, p. 225-235. 2009. Disponível em: <http://seer.cgee.org.br/index.php/parcerias_estrategicas/article/viewFile/348/351>. Consultado em: 28 jan. 2018.

ASSIS, Christiane Costa. Responsabilidade civil do Estado por danos nucleares no Brasil e nos Estados Unidos. Revista SJRS. v. 21, n. 40, p. 93-111, 2014. Disponível em: < https://www.jfrj.jus.br/revistasjrj/artigo/responsabilidade-civil-do-estado-por-danos-nucleares-no-brasil-e-nos-estados >. Consultado em: 05 fev. 2018.

BRASIL. Câmara dos Deputados. Projeto de Lei $\mathbf{n}^{\mathbf{0} 127}$ de 2013. Torna obrigatória a utilização de mecanismo de rastreamento de carga durante o transporte de materiais nucleares e radioativos. Disponível em: < https://www25.senado.leg.br/web/atividade/materias/-/materia/115808 >. Consultado em: 02 jan.2018.

BRASIL. Decreto $n^{0} 911$ de 03 de setembro de 1993. Promulga a Convenção de Viena sobre Responsabilidade Civil por danos nucleares de 21/05/1963. Congresso Nacional. Brasília, DF, set. 1993. Disponível em: < http://www.planalto.gov.br/ccivil_03/decreto/1990-1994/d0911.htm >. Consultada em: 10 fev. 2018.

BRASIL. Câmara dos Deputados. Projeto de Lei $\mathbf{n}^{\mathbf{0} 127}$ de 2013. Torna obrigatória a utilização de mecanismo de rastreamento de carga durante o transporte de materiais nucleares e radioativos. Disponível em: < https://www25.senado.leg.br/web/atividade/materias/-/materia/115808 >. Consultado em: 02 jan.2018.

BRASIL. JUSTIÇA FEDERAL. Seção Judiciária do Estado de Goiás, $8^{\text {a }}$ Vara. Ação Civil Pública n. 95-850504. Ministério Público do Estado de Goiás. Juiz Juliano Taveira Bernardes. J. 17 mar. 2000. Disponível em: < https://jus.com.br/jurisprudencia/16292/sentenca-na-acao-civil-publica-no-caso-do-acidente-radioativo-comcesio-137-em-goiania >. Consultado em: 15 dez.2017. 
BRASIL. Lei $\mathbf{n}^{0}$ 4.118, de 27 de agosto de 1962. Dispõe sobre a política nacional de energia nuclear, cria a Comissão Nacional de Energia Nuclear, e dá outras providências. Congresso Nacional. Brasília, DF, ago. 1962. Disponível em: < http://www.planalto.gov.br/ccivil_03/Leis/1970-1979/L5740.htm >. Consultada em: 11 fev. 2018

BRASIL. Lei $n^{\circ}$ 5.740, de 01 de dezembro de 1971. Autoriza a Comissão Nacional de Energia Nuclear (CNEN) a constituir a sociedade por ações Companhia Brasileira de Tecnologia Nuclear - C.B.T.N., e dá outras providências. Congresso Nacional. Brasília, DF, dez. 1971. Disponível em: < http://www.planalto.gov.br/ccivil_03/Leis/1970-1979/L5740.htm >. Consultada em: 11 fev. 2018.

BRASIL. Lei $\mathbf{n}^{\circ}$ 10.308, de 20 de novembro de 2001. Dispõe sobre a seleção de locais, a construção, o licenciamento, a operação, a fiscalização, os custos, a indenização, a responsabilidade civil e as garantias referentes aos depósitos de rejeitos radioativos, e dá outras providências. Congresso Nacional. Brasília, DF, ago. 1962. Disponível em: < http://www.planalto.gov.br/ccivil_03/Leis/LEIS_2001/L10308.htm >. Consultada em: 11 fev. 2018.

BRASIL. Lei $\mathbf{n}^{\circ}$ 6.189, de 16 de dezembro de 1974. Altera a Lei $\mathbf{n}^{\circ} 4.118$, de 27 de agosto de 1962, e a Lei $\mathbf{n}^{\circ}$ 5.740, de 1 de dezembro de 1971, que criaram, respectivamente, a Comissão Nacional de Energia Nuclear CNEN e a Companhia Brasileira de Tecnologia Nuclear - CBTN, que passa a denominar-se Empresas Nucleares Brasileiras Sociedade Anônima - NUCLEBRÁS, e dá outras providências. Congresso Nacional. Brasília, DF, dez. 1974. Disponível em: < http://www.planalto.gov.br/ccivil_03/Leis/L6189.htm >. Consultada em: 11 fev. 2018

BRASIL. Lei $\mathbf{n}^{\circ}$ 6.453, de 17 de outubro de 1977. Dispõe sobre a responsabilidade civil por danos nucleares e a responsabilidade criminal por atos relacionados com atividades nucleares e dá outras providências. Congresso Nacional. Brasília, DF, dez. 1977. Disponível em: < http://www.planalto.gov.br/ccivil_03/Leis/L6453.htm >. Consultada em: 10 fev. 2018)

BUFÁIÇAL, João Luís Felix de Sousa. Acidente com o Césio-137: Pânico Social, a Comunicação e o Imaginário Popular em Goiânia. 2012. 229 f. Dissertação (Dissertação em Direito) - Pontifícia Universidade Católica de Goiás. $\quad$ Goiânia. 2012. Disponível em: http://tede2.pucgoias.edu.br:8080/bitstream/tede/2727/1/JOAO\%20LUIS\%20FELIX\%20DE\%20SOUSA\%20B UFAICAL.pdf>. Consultado em: 28 jan. 2018.

CÂMARA DOS DEPUTADOS. Atividade Legislativa. Projeto de Lei da Câmara no 2.078, de 2007. Dispõe sobre o encerramento das atividades de uma instalação radiativa e a limitação de sua radiação residual.

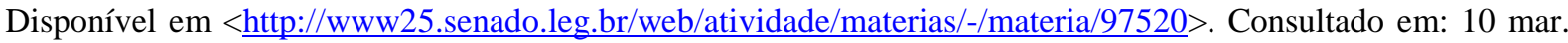
2018.

CHAVES, Elza Guedes. Goiânia é azul: o acidente com o césio 137. Revista UFG. v. 09, n. 1, 2007. Disponível em: < https://www.revistas.ufg.br/revistaufg/article/viewFile/48158/23497>. Consultado em: 20 jan. 2018.

CORREIO BRASILIENSE. Césio-137: 30 anos de um inimigo invisível. Set.2017. Disponível em: <http://especiais.correiobraziliense.net.br/cesio137/>. Consultado em: 10 dez.2017.

GABEIRA, Fernando. Goiânia, Rua 57: o nuclear na terra do sol. Rio de Janeiro: Editora Guanabara, 1987. Disponível em: < http://www.falagabeira.com.br/imgup/\%7BC85BE3D4-F5A4-45BD-A518301B107DB530\%7D_e-book\%20goiania\%20rua\%2057.pdf. >. Consultado em: 05 fev. 2018.

KURAMOTO, Renato Yoichi e APPOLONI, Carlos Alberto. Uma breve história da política nuclear brasileira. Caderno Brasileiro de Ensino da Física. v. 19, n. 3, p. 379-392, dez. 2002. Disponível em: < https://dialnet.unirioja.es/servlet/articulo?codigo=5166006/>. Consultado em: 10 jan.2017.

LOBO, Claudia. Cotejando a precaução e a prevenção na ótica da Defesa Civil: césio 137, um estudo de caso. Revista Interdisciplinar de Direito, [S.l.], v. 10, n. 2, out. 2017. ISSN 2447-4290. Disponível em: <http://faa.web1301.kinghost.net/revistas/index.php/FDV/article/view/179>. Consultado em 06 fev. 2018.

RODRIGUES, Eudes Teotônio. A responsabilidade civil do estado pelo dano nuclear e radiológico. CONPEDI 2014. 
SENADO FEDERAL. Atividade Legislativa. Projeto de Lei do Senado n ${ }^{\circ}$ 227, de 2011. Altera as Leis $n^{\circ} 9.478$, de 6 de agosto de 1997, e $\mathbf{n}^{\circ}$ 12.351, de 22 de dezembro de 2010, para garantir que parte dos recursos dos royalties e do Fundo Social sejam destinados para prevenção de desastres naturais ou provocados por vazamento radioativo, bem como para o atendimento das populações e áreas atingidas por esses desastres, e dá outras providências. Disponível em <http://www25.senado.leg.br/web/atividade/materias/-/materia /100126>. Consultado em: 18 mar.2018.

SENADO FEDERAL. Atividade Legislativa. Projeto de Lei da Câmara n 127 , de 2013. Torna obrigatória a utilização de mecanismo de rastreamento de carga durante o transporte de materiais nucleares e radioativos. Disponível em <http://www25.senado.leg.br/web/atividade/materias/-/materia/115808>. Consultado em: 18 mar.2018.

VIEIRA, Suzane de Alencar. Césio-137, um drama recontado. Estud. av., São Paulo, v. 27, n. 77, p. 217-236, 2013. Disponível em: <http://www.scielo.br/scielo.php?script=sci_arttext\&pid=S0103-40142013000100017\&lng =en\&nrm=iso>. Consultado em: 20 jan. 2018. 